\title{
Enhancing the quality of open and distance learning in China through the identification and development of learning design skills and competencies
}

\author{
Tom Olney \\ Faculty of Science, Technology, Engineering and Mathematics (STEM), \\ The Open University, Milton Keynes, UK \\ Chenxi Li \\ Faculty of Wellbeing, Education and Language Studies (WELS), \\ The Open University, Milton Keynes, UK, and \\ Juan Luo \\ Office of Academic Affairs in Secondary Vocational Education, \\ Open University of China, Beijing, China
}

\begin{abstract}
Purpose - The purpose of this paper is to identify staff skills and competencies on which Chinese open universities should focus their professional development activities in order to enhance the quality of open and distance learning (ODL) in China.

Design/methodology/approach - Data were collected from surveys of 220 academic and academic-related Chinese staff, each of whom participated in one of seven 3-day Learning Design and Course Creation (LDCC) workshops at three large regional open universities in China between 2017 and 2019. The workshops were based on the UK Open University (UKOU) approach to learning design (LD) and course creation. Using content analysis methodology, textual responses were analysed and compared against the Instructional Design Competencies framework provided by the International Board of Standards for Training, Performance and Instruction (IBSTPI).

Findings - (1) Designing instructional interventions, (2) keeping up to date with design theories, (3) communicating in order to manage stakeholders, teams and projects were the main competencies identified from the participants responses. However, these three identified competencies differed in emphasis between the institutions that took part.

Originality/value - In Western higher education institutions (HEIs), LD has developed as an important approach to improving quality. A need has been identified for robust approaches to quality and professional development opportunities to enhance teaching and learning standards in open and distance learning (ODL) in China. This paper identifies and discusses specific LD skills and competencies that could be targeted to improve the quality of ODL in China.
\end{abstract}

Keywords Learning design, Quality, Open and distance learning, IBSTPI design skills and competencies Paper type Research paper

\footnotetext{
(C) Tom Olney, Chenxi Li and Juan Luo. Published in the Asian Association of Open Universities Journal. Published by Emerald Publishing Limited. This article is published under the Creative Commons Attribution (CCBY 4.0) licence. Anyone may reproduce, distribute, translate and create derivative works of this article (for both commercial and non-commercial purposes), subject to full attribution to the original publication and authors. The full terms of this licence may be seen at http://creativecommons. org/licences/by/4.0/legalcode

The author(s) declare that no funding was received for the research, authorship and/or publication of this article
}

Enhancing quality of ODL

Received 1 December 2020 Revised 23 January 2021 30 January 2021

Accepted 1 February 2021 


\section{AAOUJ}

16,1

62

\section{Introduction}

The establishment of open universities (OUs) across Europe, North America, Asia and Africa in the latter part of the 20th century gave tertiary education a model that challenged the elite entrance requirements of traditional models, opened up access to new cohorts of students and delivered open education at distance to a large audience. OUs developed slightly differently in different parts of the world as they adapted to different cultural, political and economic realities. However, the ability to lead innovations in distance education (in areas such as teaching and learning, technologies and educational logistics) has been identified as a core component of this early model of OU education (Tait, 2008). At a global level, and despite diverse challenges, the "open" vision that OUs established is still relevant for governments committed to meeting international targets such as the UN Sustainable Development Goals. For example, if Goal 4: Quality Education is to be achieved, particularly in Asia, Latin America and Africa - "... the need for new and large-scale innovative institutions such as Open Universities remains central” (Tait, 2018, p. 18).

OUs are well-established in both the UK and China. The UKOU recently celebrated 50 years since its formation in 1969. Whilst the OU network in China was only formally established in 2010 it was built on the widespread Radio and Television Universities (RTVU) network which Deng Xiaoping put in place in the late 1970s. 24\% of all Chinese graduates (7.4 m) graduated from the government run Central RTVU between 1979 and 2009 (CRTVU, 2010). The Chinese OU network is now comprised of the central Open University of China (OUC)-replacing the CCRTVU-and five regional OUs located in Beijing, Shanghai, Jiangsu, Yunnan and Guangdong. OUC is the biggest university in the world in terms of enrolments and operates through 44 branches, over 1,000 colleges and 3,000 learning centres nationwide (Li and Chen, 2019). The heritage in distance education in China goes back further for some elements of the network. For example, 2020 saw the 60th anniversary of the founding of Shanghai OU.

The advent and promotion of online education has supercharged growth in distancebased higher education institutions (HEIs) such as OUs, as well as in the traditional campusbased tertiary sector. The Chinese Ministry of Education (MOE) reported in Education Statistics 2016 that the number of students enrolled on online higher education courses had nearly trebled since 2004, growing from $2.37 \mathrm{~m}$ to $6.45 \mathrm{~m}$ (Li and Chen, 2019). By 2015 the Chinese OU network had enrolled $3.59 \mathrm{~m}$ of these, a significant share of this huge market (OUC, 2015). An Academic Profession in Asia (APA) study in 2011-2012 of 2,480 full-time academics working in Chinese higher education found that $79.4 \%$ of them had engaged with information and communications technology (ICT)-based learning in the past year. For comparison, the same study found only $29.4 \%$ of their Japanese contemporaries had similarly engaged, demonstrating the exceptional reach of this form of teaching and learning in China (Huang, 2015).

Whilst this growth in online delivery has meant increased opportunities for OUs in both China and the UK, it has also brought challenges. In both countries, OUs have had to adapt to more competitive higher education landscapes and increasingly to justify their positions in those landscapes, as both new and conventional HEIs have adopted online, distance education models (Weller, 2017; Li and Chen, 2019). Requirements have been introduced in the UK for all HEIs (whether open or selective entry) to produce detailed evidence to the government-established Office for Students (OfS) in the form of standardised metrics laid out in the Teaching Excellence and Student Outcomes Framework (TEF, 2019). Meanwhile, in China, "it is ingrained in people's [policymakers, practitioners, researchers and the public] minds that campus education is the preferred model to produce the best qualified graduates" (Li and Chen, 2019). In these circumstances, OUs urgently require innovative approaches to establish robust quality assurance (QA) and quality enhancement (QE) mechanisms for teaching and learning. 
One such innovative approach to $\mathrm{QA} / \mathrm{QE}$ is the embedding of learning design (LD) frameworks to plan, sequence and manage teaching and learning. LD is now a discipline widely used in many Western education settings across Europe, North America and Australia, including the UKOU (Maclean and Scott, 2011; Conole and Wills, 2013; Lockyer et al., 2013; Dalziel et al., 2016; Bakharia et al., 2016). For example, the Learning Design CrossInstitutional Network (LD-CIN) group was established in October 2015 and has grown rapidly in size across Europe and Australia (LD-CIN, 2019).

This paper posits that sharing experience, skills and competencies in LD and course creation techniques, across international boundaries, can benefit OU networks everywhere and help them adapt to common factors in their changing quality and educational landscapes. This has been echoed in China where some scholars point to a need for the practical knowledge and skills that are core to working in instructional design (ID) and LD to be reflected in programmes and courses. Specifically, the panel discussion at the Association for Educational Communications and Technology (AECT) Convention in 2015 recommended that future programmes should be aligned with the Instructional Design Competencies as outlined by the International Board of Standards for Training, Performance and Instruction (IBSTPI, 2012; Chen et al., 2016).

Following a visit to China in August 2017, Tom Olney was interviewed for an article entitled "More Learning Designers are Needed" in the Chinese education industry magazine "e-Learning". The article highlighted how LD in particular could contribute to improvements in the quality of online education in China predicting that "more online education providers will focus on learning design" in the future (Chao, 2017, p. 36).

This prediction forms the basis for this research. If Chinese OUs are to focus on LD in the future, which skills and competencies should their professional development activities focus on developing?

Therefore, this paper seeks to address three research questions (RQs):

$R Q 1$. How easy or difficult did Chinese practitioners perceive it would be to implement the UKOU LDCC approach in their own institution?

RQ2. What did Chinese practitioners perceive as the most important thing that would need to change in order to make the implementation of the UKOU LDCC approach easier?

RQ3. Which IBSTPI skills and competencies might Chinese practitioners want to develop to leave them well placed to successfully implement the UKOU LDCC approach?

\section{Background and context}

Learning design and instructional design approaches at the UKOU

In Western HEIs, LD has sought to build on ID to the point where, "the two domains now overlap" (Maclean and Scott, 2011, p. 558). However, the two disciplines also differ in emphasis. For example, LD concentrates more closely than ID on the student experience, rather than that of the teacher/instructor. It also encourages taking a wider view of pedagogy, rather than focusing in at the activity level. Moreover, LD emphasises developing visualisations as a way of representing the student experience. These can then be shared and interrogated. In this way LD is therefore inextricably linked with the field of learning analytics (LA) (Conole and Wills, 2013; Lockyer et al., 2013; Dalziel et al., 2016; Olney et al., 2019).

The particular interpretation of LD that is currently in practice at the UKOU has its foundation in the findings from the OU Learning Design Initiative (OULDI) which ran from 2007 to 2012. The UKOU and 13 other higher education institutions participated in the 
AAOUJ

16,1

64

Institutional Approaches to Curriculum Design and Delivery programme which was co-funded by the not-for-profit Joint Information Systems Committee (JISC) and the European Union (EU) (Conole and Wills, 2013). Wide ranging interviews with staff at these institutions revealed a multitude of design practices. As a consequence of the OULDI, since $2012 \mathrm{LD}$ practitioners at the UKOU have sought to embed design approaches that are student-focused and based around the three principles of:

(1) Encouraging design conversations and collaboration in design

(2) Using tools, instruments and activities to describe and share designs

(3) Developing LA approaches to support and guide decision-making (Galley, 2015)

In the daily life of the UKOU, LD workshops provide a mechanism for bringing together learning designers, academics, project managers, employability specialists and technical support staff in teams to design new curriculum. Outputs from these workshops, such as student profiles, learning outcomes, activity planners and assessment strategies, are then recognised as key components in the stage-gate quality assurance process (Galley, 2015).

\section{The UKOU/Chinese OU relationship and the development of LDCC workshops}

The UKOU has a long history of scholarly exchanges with the Chinese OU network. Since 2003 around 50 visiting scholars have spent time (between 3 and 12 months) embedded at the UKOU conducting research, and since 2014 at least 25 separate delegations comprising over 350 delegates have also visited the UKOU.

One of the key components of the programme for visiting delegations has been a workshop (the LDCC workshop) that attempts to mirror, as closely as possible but on a shortened timescale, the experience of a multi-disciplinary team tasked with creating and producing a new online course at the UKOU. The workshop has been designed to not only model the LD principles and approaches outlined above but also to give the participants the opportunity to see their designs come to life on the UKOU virtual learning environment (VLE).

Typically, participants are organised into teams of five to decide on their course subject area, duration and level, allocate roles and responsibilities to one another and develop a vision statement for their course using the free, online "learning design wordwheel" (LD Wordwheel, 2016; Olney et al., 2019). The teams consider the particular needs, characteristics and learning preferences of their hypothetical students by creating one or more student profiles. Once completed, they are supported in the process of generating learning outcomes, learning activities and assessment tasks in accordance with constructive alignment principles (Biggs, 1996). The iterative design cycle process is then visualised and managed using the activity types classification framework and the allocation of anticipated student workload (Conole and Wills, 2013; Olney et al., 2019).

Participants work together to transfer their design for three to five weeks of learning onto the bespoke version of Moodle developed by the UKOU, in either Mandarin or English. The participants are encouraged to reflect throughout on the student experience they have created and on their own learning.

\section{Learning design and instructional design approaches at OU China}

In contrast to Western universities, Chinese HEIs have traditionally emphasised teaching over research activity. New academics still receive significant training in curriculum development and instruction before being asked to work with students (Huang, 2017). A proposed framework for the design of ODL courses based on the teaching practice of OUC has some elements in common with the UKOU LDCC approach, such as the analysis of 
student and learning needs, setting learning goals and the analysis of course content (Liguo and Xiaotang, 2011). Studies in the use of the GISMO statistical analysis model (Hailei and Shimei, 2018), as well as the use of the Learning Activity Management System (LAMS) and Learning Activity Design in Education (LADiE) tools (Ming, 2013) have also utilised learning analytics to help researchers interpret overall course design and the activity of individual learners.

Other researchers have introduced OUC to further approaches to learning design and course creation that show similarities to UKOU practice. Rogers (Nai Lin, 2002) presents ways to enable educators to establish a "student-centred" teaching approach for distance and open education and provide a theoretical basis for students' autonomous learning. Resource construction (Shouping, 2013), blended teaching (Wei, 2010b) and flipped classrooms (Pengjiao et al., 2015) broaden the learning model beyond the strict ODL mode of the UKOU.

However, these design frameworks remain largely theoretical and are not widely adopted in OUC practice. Part of the reason for this may be related to the complicated division of roles and responsibilities for teachers in OUC. Much of the activity of design and course creation is undertaken by "lecturers" who are often academic professors from relevant disciplines at traditional universities, or industry subject matter experts, who author the actual learning materials despite not necessarily being familiar with ODL. Responsibility for other elements, such as the development of learning activities and media resources for the VLE, is also often outsourced to technology companies. In this outsourced environment, establishing robust QA mechanisms for design and course creation is a significant challenge, since the influence of permanent staff who work in the headquarters, provincial branches, prefecture-level colleges and learning centres of the Chinese OU system (so-called "chair teachers", "responsible teachers", "tutors" and "guidance teachers") can be marginalised.

\section{Literature review}

Several QA frameworks exist to provide guidance for online and ODL. For example, the Quality assessment for e-learning: a bench marking approach manual has been developed by a core pool of eight leading HEIs through the organisation of the European Association of Distance Teaching Universities (EADTU) and is now in its third edition (EADTU, 2016). The International Council for Open and Distance Education (ICDE) has published a comprehensive global overview of quality models in online and open education (Ossiannilsson et al., 2015) whilst it has also been suggested that quality matters (QM) could offer a "... systematic quality assurance process for the design of online programs" (Ryan, 2015, p. 6).

However, a recent comprehensive literature review concluded that a holistic quality framework for Open Education did not exist and suggested a new Open Ed Quality Framework that would conceptualise quality development across three dimensions (objectives, realisations and achievements) and at three levels (micro, meso and macro) (Stracke, 2019). In this framework, learning designers and learning designs are envisaged as key stakeholders and entities occupying a role at the meso-level of the realisation dimension and thus facilitating an important QA/QE role. Other authors have suggested that competing in quality metrics designed for select entry institutions places OUs at a distinct disadvantage and therefore measurements of quality for OUs should have a different emphasis (Jung and Latchem, 2007; Tait, 2018).

Many of the concepts and activities undertaken during the LDCC workshop are linked closely with elements of quality as regards learning and teaching. For example, studentfocused design mirrors the widespread call for students to be more involved in quality enhancement practices in both Asian and Western ODL (Jung and Latchem, 2007; 
AAOUJ 16,1
Ryan, 2015). Further, the body responsible for HEI quality standards in the UK, the Quality Assurance Agency for Higher Education (QAA) in a review on UKOU practice affirms "the work being undertaken [at the UKOU] to increase student involvement in the design of modules" as an action to make academic standards more secure (QAA, 2016, p. 3). In fact, the UKOU LD strategy as a whole is praised-as part of the stage-gate design process-for being a mechanism that contributes to embedding digital literacy skills in the curriculum, assisting with supporting students and staff from diverse backgrounds and putting "student activity at the heart of the design process" (QAA, 2016, p. 29). The QAA have also highlighted the importance of considering student workload carefully in module design and ensuring these student workload expectations are consistent and explicit (QAA, 2011).

The consistent use of learning outcomes has been seen as key to the establishment of the European Higher Education Area (EHEA) through the Bologna Process (Adam, 2006). Their use has assisted with establishing common standards and methods of quality assurance between the 48 signatories (Kennedy, 2006; Magalhaes, 2010). Also, the idea that capturing learning designs through the use of LA can contribute to QA is well-supported in the literature (Lockyer et al., 2013; Galley, 2015; Dalziel et al., 2016).

A literature review of LD competency frameworks found that of those on the market IBSTPI competencies "most accurately matched" the desired key skills for learning designers. It was the only available set of standards that could "provide the necessary foundation to raise the professional profile of learning designers" (Maclean and Scott, 2011, p. 569). A strength of the IBSTPI competencies was found to be that they linked instruction closely with learning, even when the role might be distributed amongst several individuals (as in the OUC model described (Sims and Koszalka, 2008). York and Ertmer justified their use of the IBSTPI competencies as a coding framework to investigate the use of heuristics by 31 instructional designers by highlighting the fact they were recognised by professional organisations such as the AECT and the International Society for Performance Improvement (ISPI) as being crucial to graduate education programs (York and Ertmer, 2011).

As highlighted in the introduction, IBSTPI is highly regarded in China with organisations such as Sanofi University, East China Normal University in Shanghai, Renmin University of China in Beijing and Huawei in Shenzhen adopting the IBSTPI competencies in the last five years. The organisation has been established for over 30 years and has a global reach. IBSTPI provides a set of 22 core competencies, clustered into 5 domains, for free download on their website (Table 1 ) which are in turn supported by 105 more detailed performance statements (IBSTPI, 2012).

\section{Methodology \\ Participants}

The participants $(n=220)$ that took part on this study were staff engaged in some way in module development from three Chinese regional OUs (anonymised here as OUX, OUY and OUZ) based in large regional cities (over $8 \mathrm{~m}$ population). Collectively they attended seven LDCC workshops that took place on the central campus of each institution between November 2017 and June 2019.

Names, ages, titles, gender or other demographic data were not collected in order to gather honest, unbiased opinions from the largest number of participants possible. Typically, the participants were academics but there were also some developers, technical support staff and managers. Some worked on the central campus, whilst others had come in from regional branches. The three institutions were all engaged in delivering ODL, but they had developed slightly different teaching models that, in some situations, included face to face and blended learning. All participants were assured of anonymity and the purpose of the feedback was explained to them. 
Professional foundations

1. Communicate effectively in visual, oral and written form

2. Apply research and theory to the discipline of instructional design

3. Update and improve knowledge, skills, and attitudes pertaining to the instructional design process and related fields

4. Apply data collection and analysis skills in instructional design projects

5. Identify and respond to ethical, legal and political implications of design in the workplace

Planning and analysis

6. Conduct a needs assessment in order to recommend appropriate design solutions and strategies

7. Identify and describe target population and environmental characteristics

8. Select and use analysis techniques for determining instructional content

9. Analyse the characteristics of existing and emerging technologies and their potential use

Design and development

10. Use an instructional design and development process appropriate for a given project

11. Organise instructional programs and/or products to be designed, developed and evaluated

12. Design instructional interventions

13. Plan non-instructional interventions

14. Select or modify existing instructional materials

15. Develop instructional materials

16. Design learning assessment

Evaluation and implementation

17. Evaluate instructional and non-instructional interventions

18. Revise instructional and non-instructional solutions based on data

19. Implement, disseminate and diffuse instructional and non-instructional interventions

Management

20. Apply business skills to managing the instructional design function

21. Manage partnerships and collaborative relationships

22. Plan and manage instructional design projects

Table 1.

IBSPTI skills and competencies (IBSTPI, 2012)

Design

Participants were asked to respond in writing to two questions in the final session of the LDCC workshop:

Question A: On a scale of 1-4 how easy or difficult do you think it would be for your branch/ institution to implement the learning design and course creation approach we have demonstrated in the LDCC workshop over the last 3 days?

(4-point Likert scale with the options: Very easy/ easy / difficult / very difficult)

Question B: In your opinion, what is the most important thing that would need to change, in order to make the implementation [of the UKOU approach to learning design and course creation] easier?

(Open-ended text response, so the participants were not limited by options we perceived to be important)

The response rate to these questions was close to $100 \%$.

\section{Analysis}

In order to analyse the collected data, we drew on approaches from the tradition of content analysis, which is widely used in the social sciences and in education, and has been described as "a research technique for making replicable and valid inferences from data to their context" (Krippendorff, 1989, p. 403). Before analysis the data were translated from the Chinese by independent translators and the whole set checked by Chenxi Li and Juan Luo for consistency. Where respondents had identified more than one "important thing" in their 
AAOUJ 16,1

response, these were separated out into individual responses. The complete data set comprised of 315 responses.

For RQ2 the data were "cleaned" (plurals, capital letters and punctuation removed and stemming applied) and then run through word count software to create the first view of a coding list. Frequency analysis techniques using a Windows 10 version of Microsoft Word were then applied that presented each instance of a word $i n$ its context in a side bar. This enabled us to check how that word was being used and add an extra level of reliability to the analysis beyond that of a simple word count.

In order to answer RQ3, we employed a rigorous double-blind coding approach to infer how the responses mapped to the 22 IBSTPI instructional design competencies shown in Table 1, in a deductive latent content analysis. Tom Olney and Chenxi Li separately considered which of the IBSTPI competencies were being referred to in each of the first 20 responses. This mapping was shared, and the inferences discussed in order to develop a coding key. The same authors used the same approach to blindly map the next 20 comments refining the coding key as they went in a process of decontextualisation (Bengtsson, 2016). This process was repeated in blocks of 40 responses until the mapping was completed and each IBSTPI competency could be awarded an instance value. For example, a response which said, "we do not have staff specialised in learning analytics" would have resulted in coding to competencies 4, 8, 17 and 18. In order to allow for comparison across institutions, \% frequency values were then calculated by dividing the instance value for each competency by the total number of instances for all the competencies.

Content analysis approaches commonly involve establishing quantifiable outputs from large structured qualitative data sets. Whilst the coding of these comments against the IBSTPI competencies involves a risk of interpretation (as does the "counting" of all qualitative data), we make no claims to causality and only small ones to generalisability. By assigning frequency values to the comments, we hope merely to add an extra level of evidence to quantifiable verbal terms, such as lack of, lesser, equal, highly and more (Becker, 1970). In this approach, we agree with the view that the use of numbers in qualitative research is a "legitimate and valuable strategy" (Maxwell, 2010, p. 480).

\section{Findings}

$R Q 1$. How easy or difficult did Chinese practitioners perceive it would be to implement the UKOU LDCC approach in their own institution?

In total, more of the participants thought implementing the UKOU LDCC approaches into their branches or institutions would be "difficult" or "very difficult" $(61.6 \%)$ than thought it would be "easy" or "very easy" (39.4\%). When compared across institutions, however, it is clear that this view was not universally held. OUZ staff $(84.7 \%)$ clearly perceived the UKOU LDCC approaches to be much more difficult to implement that either OUX $(63.0 \%)$ or OUY $(41.1 \%)$ (see Figure 1).

RQ2. What did Chinese practitioners perceive as the most important thing that would need to change in order to make the implementation of the UKOU LDCC approach easier?

In total, 11 themes were identified in the inductive manifest content analysis of the participants' responses to Question B (responses $=220$, references $=212$ ) (see Table 2).

Whilst the qualitative nature of this data makes a direct comparison between OUX, OUY and OUZ problematic, it is possible to make certain cautious inferences about the responses from each institution compared with the others. 


\section{Ease of implementation for OUX, OUY \& OUZ}

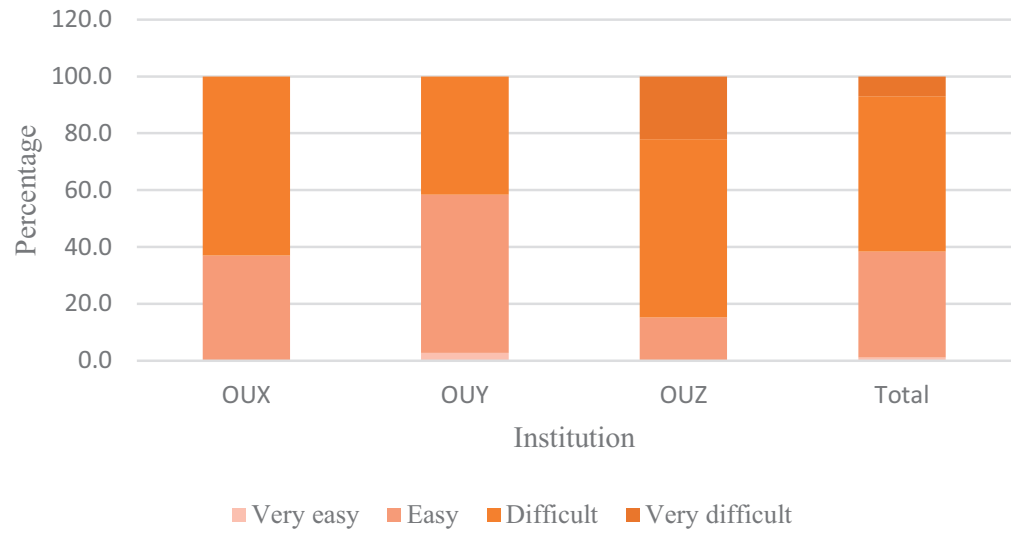

Enhancing quality of ODL

69

Figure 1.

The perceived ease of implementation by institution (\%)

\begin{tabular}{|c|c|c|c|c|c|c|}
\hline & Theme & OUX & OUY & OUZ & Total references & \\
\hline 1 & The way teams are established and operated (teamwork) & 18 & 14 & 32 & 64 & \\
\hline 2 & Technical systems (platform/website/IT) & 16 & 19 & 9 & 44 & \\
\hline 3 & Student-centred approach to pedagogy & 11 & 14 & 11 & 36 & \\
\hline 4 & Bureaucratic systems (organizational/institutional/national) & 11 & 1 & 8 & 20 & \\
\hline 5 & Time (academic workload) & 4 & 5 & 5 & 14 & \\
\hline 6 & Use of data and LA & 7 & 2 & 0 & 9 & \\
\hline 7 & Assessment design & 2 & 6 & 0 & 8 & \\
\hline 8 & Teaching and learning pedagogy (general) & 6 & 2 & 0 & 8 & \\
\hline 9 & Ability of students to learn & 4 & 0 & 0 & 4 & \\
\hline 10 & Designing learning outcomes & 1 & 1 & 1 & 3 & \\
\hline \multirow[t]{2}{*}{11} & Engagement of students & 1 & 1 & 0 & 2 & Table 2. \\
\hline & Total & & & & 212 & Frequency of themes \\
\hline
\end{tabular}

For example, OUX staff perceived the development of technical systems $(n=16)$ to be of almost equal importance to that of teamwork $(n=18)$. OUX staff also referenced the use of data and LA $(n=7)$ far more frequently than the other institutions.

The identification of updates to bureaucratic systems was significantly lower for OUY staff $(n=1)$ than for either of the other two institutions. OUY staff instead placed disproportionate emphasis on technical systems needing to be updated $(n=19)$ when compared with the total of all references.

OUZ staff referenced teamwork more frequently than the other two institutions $(n=32)$. Teamwork made up almost half of all the thematic references that were identified for them. This emphasis was balanced by a comparative lack of references for technical systems $(n=9)$, which suggested that OUZ felt well placed to cope with that particular challenge. No respondents from OUZ identified general pedagogy, designing assessment, LA, engagement or ability of students to be themes that might need attention.

Whilst the lack of time available for course design and creation was not referenced in great numbers, it was consistently mentioned by a significant minority in all the institutions (OUX $n=4$, OUY $n=5$, OUZ $n=5$ ). 
AAOUJ

16,1
RQ3. Which IBSTPI skills and competencies might Chinese practitioners want to develop to leave them well-placed to successfully implement the UKOU LDCC approach?

The results from the coding of the participants' comments against the IBSTPI competencies suggests several areas in which ongoing professional development should focus if the UKOU LDCC approach were to be adopted (see Figures 2 and 3).

Competencies 12, 14 and 15 received high levels of coding. Grouped together in the "Design and Development" domain, this coding can be interpreted to suggest that the participants felt they would benefit from skills that help them design learning activities (instructional interventions). The related performance statements for these competencies explicitly reference the use of technical systems, student-centred approaches and learning outcomes which were identified as themes in RQ2.

This interpretation is supported by the similarly high coding for competencies 2 and 3 which indicate a potential focus on keeping up to date with developments in design theory and how to apply them to design practice. Grouped in the "Professional Foundations" domain, the related performance statements also reference the use of student-centred design approaches, technical systems and teaching and learning pedagogy (general) themes identified in RQ2.

The high coding for competencies 1, 20,21 and 22 can be interpreted to suggest a need for professional development that focuses on developing communication skills to successfully manage stakeholder relationships, teams and projects. The related performance statements for these competencies reference the ways teams are established and operated that were identified as a theme in RQ2.

On some occasions, respondents' comments did not reference directly to any IBSTPI competencies. For example, "lack of time" (academic workload) was an identified theme but outside the scope of the IBSTPI framework. Also, some respondents made comments about changes to the LDCC workshop itself, rather than the implementation of the LDCC approach in their own context. In these cases, the comments were coded as "not valid".

\section{Discussion and analysis}

The IBSTPI competencies have been used in the past as the basis for a discussion around what were called, competencies for the new-age instructional designer (Sims and Koszalka, 2008). Here, drawing on this work for reference and inspiration, we propose a similar elaboration but informed by the findings from our study and renamed competencies for the Chinese ODL designer.

\section{The learning designer as a professional}

Competency 3, which includes performance statements that focus on "engaging in professional development activities in design and educational technologies" as well as "maintaining professional networks", was heavily referenced in the analysis. Instructional designers need to stay up to date with developments in the constantly evolving process of evaluating, reviewing and refining design (Sims and Koszalka, 2008). LA has uncovered new ways to do this and the UKOU LDCC approach is underpinned by such an implementation (Olney et al., 2019). In 2012, the IBSTPI competencies were updated to reflect this growing LA focus by creating a fifth domain: evaluation and implementation. Competencies 4 and 8 are also relevant here. Designers have opportunities to be supported and published by professional bodies such as the Society of Learning Analytics Research (SoLAR), and the LD$\mathrm{CIN}$ which has recently welcomed international attendees from Australia, Ireland, Russia and 
Enhancing

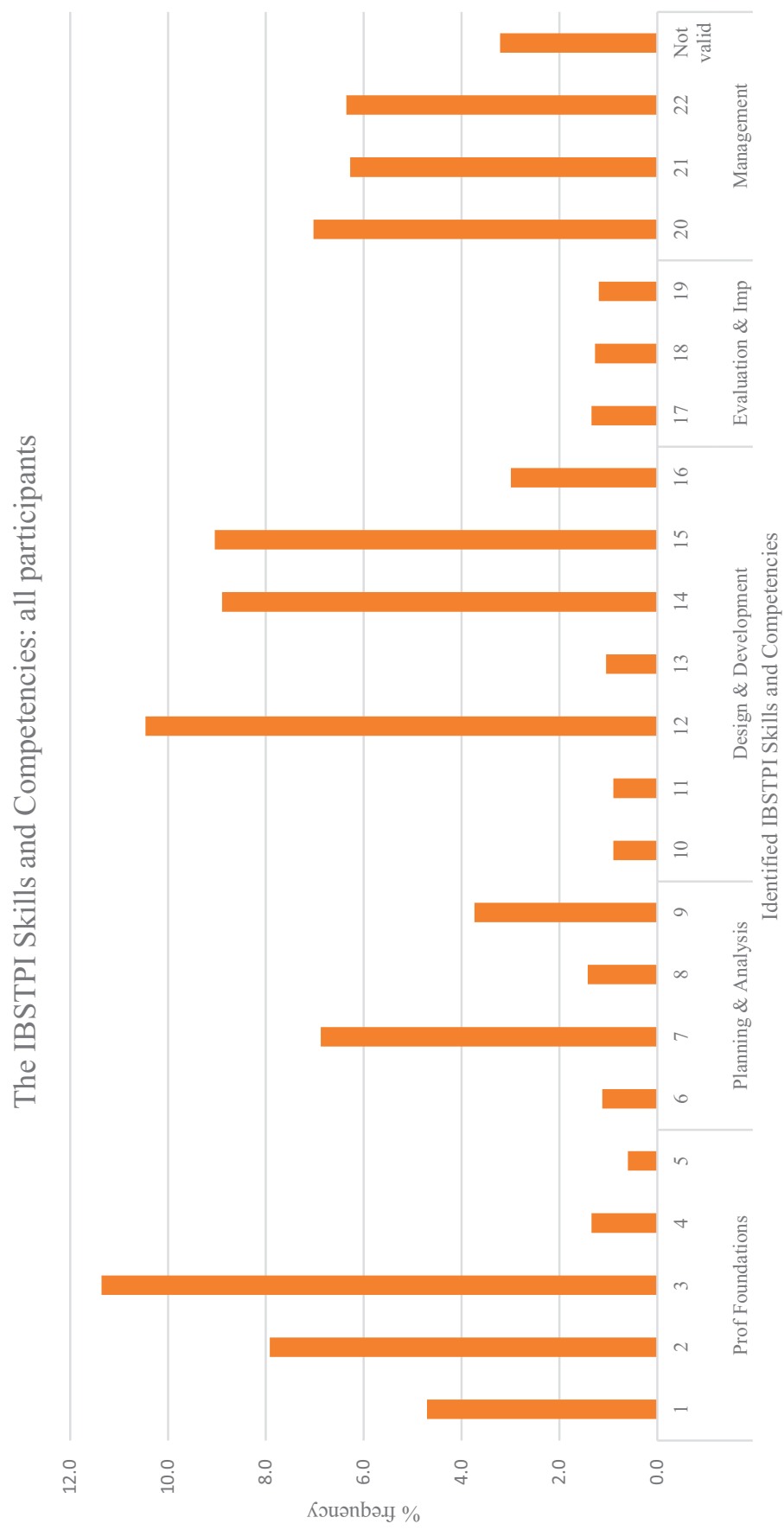
quality of ODL

Figure 2.

$\%$ frequency of references to IBSTPI skills and competencies (all participants) 
AAOUJ
16,1

72

Figure 3.

$\%$ frequency of references to IBSTPI skills and competencies (comparison of OUX, OUY and OUZ)

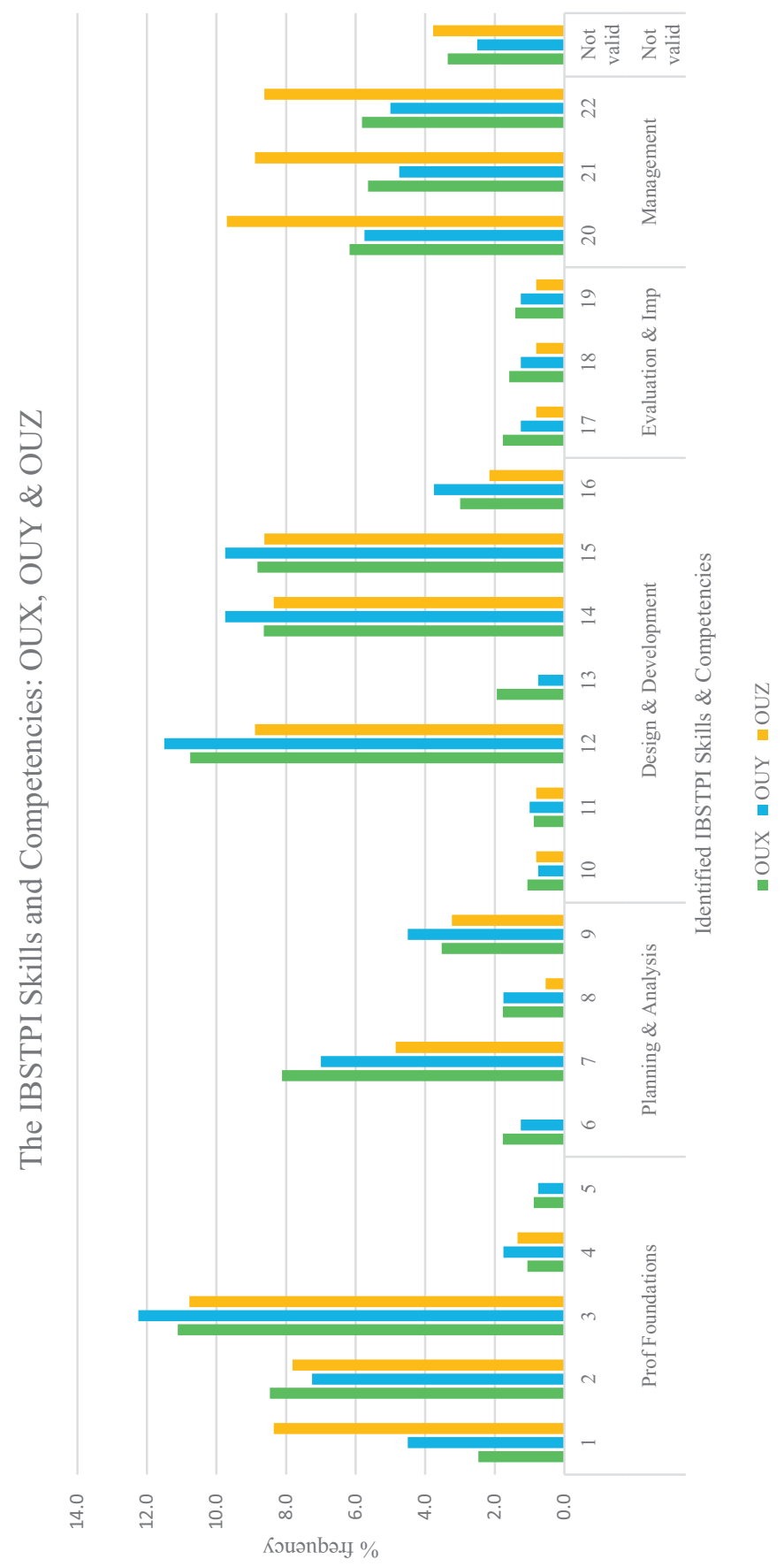


China amongst others to discuss global collaboration (LD-CIN, 2019). An ongoing need for further professional development amongst OU staff was also identified as an explicit concern by several global OU leaders (Tait, 2018) and other studies have similarly highlighted that teachers in Chinese OUs often lack professional development opportunities (Yang, 2014). This research supports the idea that China-based OU staff could benefit from increased involvement in professional networks.

\section{The learning designer as a collaborator}

Skills related to the ways teams are established and operated was highlighted by the high rates of coding for competencies 1,20,21 and 22, and a multi-disciplinary approach to design has been considered vital to good practice (Sims and Koszalka, 2008). Current collaborative practice at the UKOU is contextualised, not uniform, and constantly evolving. Initially, a centralised LD team was established to work across different subject areas to provide coordination, guidance and advice on design practice (Galley, 2015). Whilst this approach has its benefits, other research has demonstrated the value of relationships built on rapport and "familiarity in course content" from the LD side (Chao et al., 2010, p. 113). Recent re-organisations at the UKOU have resulted in the $\mathrm{LD}$ team now being comprised of smaller, faculty-facing teams. In fact, in some faculties, the lead-learning designer reports into academic governance pathways, rather than centralised ones, which has been seen to encourage faculty buy-in (Miller and Stein, 2016).

Establishing multi-disciplinary collaborative design practice can be challenging. Academic content experts may have legitimate concerns over the ownership of the courses they create, and with which their professional reputations are associated, whilst differences in the levels of contributors' expertise and the degree of course development input required have also been identified as problematic (Chao et al., 2010; Halupa 2019). However, the experience of the UKOU supports the view that despite some concerns about the collaborative approach being time consuming, "it can reduce the amount of time and work spent fixing problems later, the kind that, if they arise, can compromise the quality of a course" (Chao et al., 2010, p. 115).

\section{The learning designer as a communicator}

A strong consensus exists that being able to communicate effectively in visual, oral and written form is of utmost importance to the instructional or learning designer (Sims and Koszalka, 2008; York and Ertmer, 2011: Chao et al., 2010; Maclean and Scott, 2011; Chen et al., 2016; Halupa, 2019). Despite predictions that written communication would become the "primary interactive element" (Sims and Koszalka, 2008, p. 572), LD workshops at the UKOU still stress the value of face-to-face interaction in building rapport and relationships in teams. This is reflected in the high coding rate for competency 1 , which is built around performance statements that include being able to "deliver presentations", "listen actively", "provide feedback", "consider audience", "resolve conflict, negotiate outcomes and facilitate meetings".

One of the keys to effective teamwork in the design space is having well-written and communicated policies and guidance that explain the delineation of roles and responsibilities and can be used to defuse potential conflict (Halupa, 2019). As the UKOU approach has matured, a faculty website has been created that serves to communicate the LDCC process with a chronological presentation of induction and guidance materials. Recent evaluation found that $90 \%$ of academics and support staff agreed that this had assisted them in their work (Olney, 2020). The research presented here suggests that Chinese OUs should focus on professional development activities that build facilitation and communication skills. 


\section{AAOUJ 16,1}

The learning designer as a student-focused educator

The job title instructional designer, with its emphasis on teaching, is often viewed as rather outdated and alternatives, such as learning environment architect (Sims and Koszalka, 2008) or learning designer (Maclean and Scott, 2011) have also been proposed. Both of these newer options acknowledge the primary goal of curriculum design as being to design student-facing learning. High coding for competencies such as 2, 7, 12, 14 and 15 that relate to considering learning from the student's perspective were noted and suggest more professional development in this area is needed. These competencies contain performance statements that focus on "applying research and theory", "determining target population and environments via data" and "aligning with learning outcomes and other content analyses of students".

Perhaps this is not surprising. Only $4.3 \%$ of the Chinese academics who responded to an APA study considered students to be the primary actor in influencing the evaluation of their teaching activities, compared to $46.8 \%$ who considered this primary actor to be "institutional managers" and 14.8\% who identified "government or external stakeholders" (Huang, 2015). In considering the upcoming transition of the five regional RTVUs to Chinese OUs, a studentcentred approach is "the essence of open learning" (Wei, 2010a, p. 48). The findings from this study suggest that the practice of designing student-centred learning should be the key underlying principle of future professional development activities to improve the quality of ODL in China.

If improved quality in ODL through LD is the goal, this study provides strong evidence that the Chinese ODL learning designers of the future would benefit from professional development that considers their needs as a professional, collaborator, communicator and student-focused educator.

\section{Limitations and future work}

The scope of this study is limited to the three RQs and any attempt to explain the differences in the responses between OUX, OUY and OUZ would require a much more complex, qualitative study. The findings presented here correlate closely with the design of the LDCC workshop. Further work would also be required to establish whether there is a causal relationship between the two.

Whilst the IBSTPI competency framework, in particular due to its emphasis on instruction over learning, is accepted as not being perfect for all UK HEIs (Maclean and Scott, 2011), it is well-supported in the literature as the leading global framework for assessing design competencies in higher education (Sims and Koszalka, 2008; York and Ertmer, 2011; Chao et al., 2010; Chen et al., 2016; Halupa, 2019).

Also, the participants from the three Chinese OUs only represent a small sample of the full number of staff involved in design and course creation, and the impact of their exact roles, age, gender and prior experience on their responses were not controlled for here. Despite the agenda and the main facilitators of the LDCC workshop staying the same between workshops, like any good teaching there were also minor tweaks and improvements that may have led to subtle changes in emphasis in delivery along the way.

Ongoing collaboration in this field between the UKOU and the Chinese OU network continues and several LDCC workshops, with these and other Chinese HEIs, have taken place since those documented here. To date, over 600 Chinese staff have participated in the LDCC Workshop. The findings from this study have been used to inform the development of targeted professional development activities, such as in team building with OUZ, for example, and further work that aims to measure the impact of the LDCC workshop is planned. 


\section{Conclusions}

This study set out to answer three research questions related to improving the quality of ODL with learning design. It used data gathered from 220 Chinese OU staff from three open universities who participated in seven separate LDCC workshops between November 2017 and June 2019. The study found that overall, more of the Chinese participants considered implementing the LDCC approach in their own institution to be "difficult" or "very difficult" than "easy" or "very easy", although there were differences noted between the HEIs. It was also found that the Chinese participants felt that teamwork, technical systems, studentcentred pedagogy and bureaucratic systems were the most important things that would need to change in order to make the implementation of the UKOU LDCC approach easier. Again, differences were noted between the HEIs. Further, the study found that designing instructional interventions, keeping up to date with design theories and communicating in order to manage stakeholders, teams and projects were the most needed skills and competencies required to implement the UKOU LDCC approach, although, here too, differences in emphasis between the HEIs were identified.

If the prediction that, "more online education providers will focus on learning design" (Chao, 2017, p. 36) in China to improve the quality of ODL is to be realised effectively, the findings of this study suggest the way forward should be to focus attention on the Chinese learning designer as a professional, collaborator, communicator and student-focused educator.

\section{References}

Adam, S. (2006), An Introduction to Learning Outcomes, available at: https://citeseerx.ist.psu.edu/ viewdoc/download?doi=10.1.1.498.8663\&rep=rep1\&type $=$ pdf (accessed 30 Jan 2021).

Bakharia, A., Corrin, L., De Barba, P., Kennedy, G., Gašević, D., Mulder, R., Williams, D., Dawson, S. and Lockyer, L. (2016), "A conceptual framework linking learning design with learning analytics", Proceedings of the Sixth International Conference on Learning Analytics and Knowledge, Edinburgh, April 2016, pp. 329-338, doi: 10.1145/2883851.2883944.

Becker, H. (1970), "Field work evidence”, in Becker, H. (Ed.), Sociological Work: Method and Substance, Transaction Books, New Brunswick, NJ, pp. 39-62.

Bengtsson, M. (2016), "How to plan and perform a qualitative study using content analysis", NursingPlus Open, Vol. 2, pp. 8-14, doi: 10.1016/j.npls.2016.01.001.

Biggs, J. (1996), "Enhancing teaching through constructive alignment", Higher Education, Vol. 32 No. 3, pp. 347-364, doi: 10.1007/BF00138871.

Chao, P. (2017), More Learning Designers are Needed, e-Learning (Zàixiàn xuéxí), Distance Learning/ Education Journal Press, Beijing, pp. 26-36.

Chao, I., Saj, T. and Hamilton, D. (2010), "Using collaborative course developments to achieve online course quality standards", International Review of Research in Open and Distance Learning, Vol. 11 No. 3, pp. 106-126, doi: 10.19173/irrodl.v11i3.912.

Chen, H., Dong, L., Tomita, K. and Eunkyung, M. (2016), "Educational technology and instructional design in East Asia: program curricula and career opportunities", TechTrends, Vol. 60 No. 6, pp. 525-527, doi: 10.1007/s11528-016-0112-x.

Conole, G. and Wills, S. (2013), "Representing learning designs - making design explicit and shareable", Education Media International, Vol. 50 No. 1, pp. 24-38, doi: 10.1080/09523987.2013. 777184 .

CRTVU (2010), Education Statistics Yearbook of RTVU in China, China RTVU Press, Beijing.

Dalziel, J., Conole, G., Wills, S., Walker, S., Bennett, S., Dobozy, E., Cameron, L., Badilescu-Buga and Bower, M. (2016), "The Larnaca declaration on learning design", Journal of Interactive Media in Education, Vol. 1 No. 7, pp. 1-24, doi: 10.5334/jime.407.

\section{Enhancing quality of ODL}


AAOUJ 16,1

EADTU (2016), Quality Assessment for E-Learning: A Benchmarking Approach, 3rd ed., European Association of Distance Teaching Universities, Maastricht, available at: http://e-xcellencelabel. eadtu.eu/images/E-xcellence_manual_2016_third_edition.pdf (accessed 27 March 2020).

Galley, R. (2015), "Learning design at the Open University: introducing methods for enhancing curriculum innovation and quality", Quality Enhancement Report Series, Vol. 1, available at: http://article.iet.open.ac.uk/Q/QE\%20report\%20series/2015-QE-learning-design.pdf (accessed 30 Jan 2021).

Hailei, P. and Shimei, H. (2018), "Reflection on instructional design of online courses from the perspective of learning analysis: a case study of "learning and development of children aged 3-6 Years' of preschool education in Beijing open university", E-education Research, Vol. 301 No. 5, pp. 53-59.

Halupa, C. (2019), "Differentiation of roles: instructional designers and faculty in the creation of online courses", International Journal of Higher Education, Vol. 8 No. 1, pp. 55-68, doi: 10.5430/ijhe. v8n1p55.

Huang, F. (2015), "A comparative study of academic staff teaching activities between Japan and China: based on national surveys in 2011-2012", RIHE International Seminar Reports, Research Institute for Higher Education, Hiroshima University, pp. 45-59, available at: https://eric.ed. gov/?id=ED574230 (accessed 30 January 2021).

Huang, F. (2017), "The impact of mass and universal higher education on curriculum and instruction: case studies of China and Japan”, Higher Education, Vol. 74 No. 3, pp. 507-525, doi: 10.1007/ s10734-016-0061-5.

IBSTPI (2012), "Instructional design skills and competencies", available at: https://ibstpi.org (accessed 22 Dec 2019).

Jung, I. and Latchem, C. (2007), "Assuring quality in Asian open and distance learning", Open Learning: The Journal of Open, Distance and E-Learning, Vol. 22 No. 3, pp. 235-250, doi: 10.1080/ 02680510701619885.

Kennedy, D. (2006), "Writing and using learning outcomes: a practical guide from University College Cork", available at: https://cora.ucc.ie/handle/10468/1613 (accessed 30 Jan 2021).

Krippendorff, K. (1989), "Content analysis”, in Barnouw, E., Gerbner, G., Schramm, W., Worth, T. and Gross, L. (Eds), International Encyclopaedia of Communication, Oxford University Press, New York, NY, Vol. 1, pp. 403-407, available at: http://repository.upenn.edu/asc_papers/226 (accessed 23 December 2019).

LD Wordwheel (2016), “The learning design wordwheel”, available at: http://www.open.edu/openlearn/ wordwheel (accessed 30 January 2021).

LD-CIN (2019), "International learning design cross-institutional network", available at: https:/sites. google.com/site/learningdesignsig/home?authuser $=0$ (accessed 8 Jan 2020).

Li, W. and Chen, N. (2019), "Chapter 2: China”, in Zawacki-Richter, O. and Qayyum, A. (Eds), Open and Distance Education in Asia, Africa and the Middle East, Springer Briefs in Education, Singapore, available at: https://library.oapen.org/handle/20.500.12657/23272 (accessed 3 January 2021).

Liguo, F. and Xiaotang, Y. (2011), "Research on pattern of course teaching design in distance and open education”, China Educational Technology, Vol. 296 No. 9, pp. 53-60, ISSN 1006-9860.

Lockyer, L., Heathcote, E. and Dawson, S. (2013), "Informing pedagogical action: aligning learning analytics with learning design", American Behavioural Scientist, Vol. 57 No. 10, doi: 10.1177/ 0002764213479367.

Maclean, P. and Scott, B. (2011), "Competencies for learning design: a review of the literature and a proposed framework”, British Journal of Educational Technology, Vol. 42 No. 4, pp. 557-572, doi: 10.1111/j.1467-8535.2010.01090.x.

Magalhaes, A. (2010), "The creation of the EHEA, learning outcomes and the transformation of educational categories in higher education”, Educação, Sociedade and Culturas, available at: 
https://repositorio-aberto.up.pt/bitstream/10216/62440/2/85633.pdf (accessed 30 January 2021).

Maxwell, J. (2010), "Using numbers in qualitative research", Qualitative Inquiry, Vol. 16 No. 6, pp. 475-482, doi: 10.1177/1077800410364740.

Miller, S. and Stein, G. (2016), "Finding our voice: instructional designers in higher education", Educause Review, available at: https:/er.educause.edu/articles/2016/2/finding-our-voiceinstructional-designers-in-higher-education (accessed 15 March 2020).

Ming, L. (2013), "Research on teaching design of learning activity in open education-case study of quality of ODL "College English”, E-education Research, Vol. 242 No. 6, pp. 53-56.

Nai Lin, C. (2002), "A brief disussion on teaching designing of modern distance open education", Journal of Jiangsu Radio and Television, Vol. 13 No. 5, pp. 5-10.

Olney, T. (2020), "Review of learning design in STEM", Unpublished Manuscript.

Olney, T., Rienties, B. and Toetenel, L. (2019), "Chapter 6: gathering, visualising and interpreting learning design analytics to inform classroom practice and curriculum design. Learning analytics in the Classroom", in Lodge, J., Horvath, J. and Corrin, L. (Eds), Translating Learning Analytics for Teachers, Routledge Press, ISSN 1351113011.

Ossiannilsson, E., Williams, K., Camilleri, A. and Brown, M. (2015), Quality Models in Online and Open Education Around the Globe. State of the Art and Recommendations, International Council for Open and Distance Education - ICDE, Oslo, available at: https://static1.squarespace.com/static/ 5b99664675f9eea7a3ecee82/t/5bb8e80f652deaada670aee8/1538844696866/icdequalitymodels22. pdf (accessed 27 March 2020).

OUC (2015), Open University of China Annual Report 2015, OUC Press, Beijing.

Pengjiao, W., Tingting, D., Yunan, C. and Xiangmin, Z. (2015), "The applied research of SPOC-based teaching design pattern in flipped classroom in open university", China Educational Technology, Vol. 347 No. 12, pp. 79-85, ISSN 1006-9860.

QAA (2011), "Explaining contact hours", available at: https:/www.qaa.ac.uk/docs/qaa/quality-code/ contact-hours-guidance.pdf?sfvrsn=cc45f981_8 (accessed 23 December 2019).

QAA (2016), "Higher education review of the open university", available at: https:/www.qaa.ac.uk/ docs/qaa/reports/the-open-university-her-15.pdf?sfvrsn=2783f481_4 (accessed 23 December 2019).

Ryan, T. (2015), "Quality assurance in higher education: a review of literature", Higher Learning Research Communications, Vols 5-4, doi: 10.18870/hlrc.v5i4.257.

Shouping, H. (2013), "Reflections on the teaching design in the resource construction of open university", Journal of Yunnan Open University, Vol. 15 No. 12, pp. 7-9.

Sims, R. and Koszalka, T. (2008), "Competencies for the new-age instructional designer", Handbook of Research on Educational Communications and Technology, Vol. 3, pp. 569-575, available at: http://citeseerx.ist.psu.edu/viewdoc/download?doi=10.1.1.955.5090\&rep=rep1\&type=pdf\# page $=602$ (accessed 03 January 2021).

Stracke, C. (2019), “Quality frameworks and learning design for open education”, International Review of Research in Open and Distributed Learning, Vol. 20 No. 2, pp. 180-202, doi: 10.19173/irrodl. v20i2.4213.

Tait, A. (2008), “What are open universities for?”, Open Learning, Vol. 23 No. 2, pp. 85-93, doi: 10.1080/ 02680510802051871.

Tait, A. (2018), "Open universities: the next phase", Asian Association of Open Universities Journal, Vol. 13 No. 1, pp. 13-23, doi: 10.1108/AAOUJ-12-2017-0040.

TEF (2019), "Teaching excellence framework", available at: https://www.officeforstudents.org.uk/ advice-and-guidance/teaching/what-is-the-tef/ (accessed 23 December 2019).

Wei, R. (2010a), "China's radio and TV universities: reflections on theory and practice of open and distance learning”, Open Learning, Vol. 25 No. 1, pp. 45-56, doi: 10.1080/02680510903482199. 
AAOUJ

16,1
Wei, P. (2010b), "Online teaching design of distance education based on blending learning", Journal of Gansu Radio and TV University, Vol. 20 No. 3, pp. 66-68.

Weller, M. (2017), "My part in the battle for open (universities)", The Ed Techie Blog, Vol. 25, October, available at: http://blog.edtechie.net/ou/my-part-in-the-battle-for-open-universities/ (accessed 23 December 2019).

Yang, Z. (2014), Transformation and Systematic Development; Research Report of China RTVUs, China Central and Radio TV University Press, Beijing.

York, C. and Ertmer, P. (2011), "Towards an understanding of instructional design heuristics: an exploratory Delphi study", Educational Technology Research and Development, Vol. 59 No. 6, pp. 841-863.

Zhang, W. and Li, W. (2019), "Transformation from RTVUs to Open Universities in China: current state and challenges", International Review of Research in Open and Distributed Learning, Vol. 20 No. 4, pp. 1-20, doi: 10.19173/irrodl.v20i4.4076.

\section{Corresponding author}

Tom Olney can be contacted at: tom.olney@open.ac.uk

For instructions on how to order reprints of this article, please visit our website: 